\title{
A construção de novos mundos através do som. Estudo de caso do game para dispositivos móveis DarkEcho.
}

The construction of new worlds through sound. Case study of the game for mobile devices DarkEcho.

\author{
Júlio Alessi
}

games, sound design, dispositivos móveis, intermidialidade.

\begin{abstract}
Este trabalho propõe um estudo de caso do game DarkEcho, para dispositivos móveis, no qual a interface gráfica é articulada prioritariamente pela linguagem sonora, o que é incomum, já que no universo dos games a imagem tem maior destaque, ficando o som geralmente em segundo plano. Na análise do jogo, foram levantadas diversas possibilidades do uso do som na mediação do processo audiovisual, na recriação de um mundo de terror e suspense, em um processo de remediação e alusão a diversos símbolos do gênero através de uma experiência sonora imersiva e interativa.
\end{abstract}

games, sound design, mobiles, intermidiality.

This work proposes a case study of the game DarkEcho, for mobile devices, in which the graphical interface is articulated primarily by the sound language, which is unusual, since in the universe of games the image is more prominent, being the sound usually in second plan. In the analysis of the game, several possibilities of the use of sound in the mediation of the audiovisual process, in the recreation of a world of terror and suspense, in a process of remediation and allusion to diverse symbols of the genre through an immersive and interactive sound experience were raised.

\section{Introdução}

A partir do desenvolvimento de dispositivos eletrônicos, como o computador, foi possível criar e adaptar vários jogos e livros para os meios digitais. Esse fenômeno, portanto, não é recente. Porém, o que mudou, nos últimos anos, foram as formas de manipulação dos conteúdos, que anteriormente eram realizadas através do mouse e teclado (o que, muitas vezes, não era um processo natural e intuitivo) e passaram a ser uma interação direta entre a tela e os toques do usuário.

Com o lançamento dos tablets, principalmente o iPad da Apple, as interações entre homem e máquina sofreram mudanças consideráveis, pois tornou-se possível, através dos dedos ou mesmo movendo o dispositivo para os lados, utilizando sensores como o acelerômetro, pode interagir com os conteúdos de forma mais espontânea e dinâmica, possibilitando assim arrastar, soltar, pressionar ou mesmo girar o dispositivo para que ocorra a reação em tempo real. A ação de virar a página, por exemplo, é acionada com um deslizar de dedos.

Muitos usuários, devido a essa facilidade, têm migrado para os tablets e outros dispositivos móveis, principalmente para usufruir os games que tiveram versões em alguns casos exclusivas para essas mídias, devido às interações diferentes de consoles ou computadores desktop. É possível pilotar uma nave ou um carro girando o tablet como se fosse um volante, por exemplo.

Geralmente as obras criadas buscaram explorar com mais ênfase o processo de animação dos objetos utilizando um agenciamento que é alterado de acordo com a manipulação do usuário, no qual se pode manipular os objetos interativos girando, inclinando ou balançando o dispositivo móvel que reage de forma bastante intuitiva.

\author{
Anais do 9 CIDI e 9 CONGIC \\ Luciane Maria Fadel, Carla Spinillo, Anderson Horta, \\ Cristina Portugal (orgs.) \\ Sociedade Brasileira de Design da Informação - SBDI \\ Belo Horizonte | Brasil | 2019 \\ ISBN 978-85-212-1728-2
}

Proceedings of the 9th CIDI and 9th CONGIC

Luciane Maria Fadel, Carla Spinillo, Anderson Horta, Cristina Portugal (orgs.)

Sociedade Brasileira de Design da Informação - SBDI

Belo Horizonte | Brazil | 2019

ISBN 978-85-212-1728-2 
Outra tecnologia que despontou consideravelmente nesses aplicativos foram as imersões tridimensionais que contam com o uso de um óculos estereoscópico, como o Google Cardboard, no qual o usuário tem duas imagens na tela (direita e esquerda) que são separadas pelos óculos, tendo uma visão imersiva tridimensional e interativa da obra, pois, para cada lado que o usuário se vire é possível observar a imagem em diferentes ângulos que acompanham o movimento de sua cabeça, ampliando a sensação imersiva.

Essas tecnologias ampliaram o leque de possibilidades criativas no universo audiovisual, fomentando novas formas narrativas ou experiências imersivas. Vários projetos foram desenvolvidos em diferentes áreas com focos distintos como entretenimento ou educação, que possibilitam ao usuário "mergulhar" na obra. Experimentando desde um passeio de montanha russa ou como o protagonista de uma narrativa ou o explorador de complexos arquitetônicos ou mesmo visitante de museus. Podendo observar uma história com a visão em primeira pessoa, explorando o ambiente virtual, definindo a hierarquia dos pontos de vista e dos elementos a serem observados. Como o leitor fica livre para olhar em qualquer direção dentro da realidade virtual, o som passa a ter um papel ainda mais importante, afinal, ele pode ser explorado para conduzir a experiência narrativa.

\section{0 uso do som nos dispositivos móveis.}

Assim como acontece em muitas obras cinematográficas, como destaca Belleboni (2004), pôde-se notar, em uma primeira análise dos dispositivos móveis, que a linguagem sonora nos aplicativos muitas vezes fica em segundo plano.

[...] verificamos que desde o início da história do cinema, o som foi submetido aos imperativos da imagem, expressando, de certo modo, a hegemonia da imagem e do visual que caracteriza a cultura da passagem da Modernidade para a Contemporaneidade. (Belleboni, 2004, p.3)

Podemos observar que apesar do desenvolvimento de tecnologias que garantem uma experiência sonora de excelente qualidade de reprodução e que poderiam ampliar consideravelmente as experiências nos usuários em games para dispositivos móveis, a concepção e desenvolvimento sonoro para esses dispositivos não obtiveram a mesma atenção. Em diversos games temos um projeto sonoro mimético que decalca o mundo real que é reproduzido no game como em produções cinematográficas tradicionais.

A trilha musical segue uma lógica de pano de fundo, que às vezes denota uma emoção quase pré-determinada pelo repertório de trilhas clássicas do cinema. Os games em geral desenvolvidos para esse tipo de dispositivo seguem a lógica da escritura fílmica tradicional, seguindo um repertório clássico musical.

Como os dispositivos atuais estão repletos de tecnologias de reprodução audiovisual interativa e imersiva, vislumbramos a oportunidade de ampliar o uso do som nas relações audiovisuais, entre os usuários e os dispositivos, ampliando as experiências sensoriais vivenciadas através das possibilidades do uso do som imersivo 3D, com base em tecnologias de reprodução em dolby estéreo, que possibilita, além da visualização da imagem tridimensional interativa, podem ampliar as percepções e sensações sonoras. As opções tecnológicas permitiram a reprodução em surround ${ }^{1}$, através de diversos dispositivos sonoros, mesmo em headphones, como o Cooler Master CM StormSirus.

Como apontam Dau e Poulsen apud Valbom (2006, p. 50)

No nosso dia a dia, ouvir, significa muitas vezes determinar a origem da fonte de som. O que chega aos nossos ouvidos é, com efeito, uma mistura dessas fontes de som, com reflexões e difrações de paredes, mobiliário, chão, árvores, postes, conforme o Cap. 2 Som, Tecnologias Áudio e

Espacialização Sonora 50 ambiente/espaço em que nos encontramos. Desta mistura das fontes de som, o sistema auditivo retira apenas a informação relevante.

\footnotetext{
${ }^{1}$ Dispositivo de som que serve para enriquecer a reprodução sonora para os ouvintes, através de uma fonte de áudio com canais independentes, recriando um ambiente imersivo e realista. Essa tecnologia está disponível em cinemas, home theater e fones dolby estéreos.
} 
Essa escuta recriada em um ambiente virtual pode de certa forma ampliar o processo perceptivo espacial da obra, enriquecendo a experiência audiovisual. Também tem a liberdade de criar novos contextos sonoros que rompem a relação mimética, desenvolvendo dessa forma novos agenciamentos audiovisuais.

\section{Game com predomínio do som em relação à imagem}

Os games atuais seguem uma tendência em recriar mundos fictícios com a máxima resolução e fidelidade através de gráficos em alta resolução a partir do formato Full HD 1920×1080 pixels, apontando para novos games em 4K $3840 \times 2160$ pixels. Além de uma evolução tecnológica em relação à qualidade de exibição da imagem, temos também uma preocupação com a imersão do jogador nos games através de óculos de realidade virtual e imagens em 3D.

O desenvolvimento dessas interfaces hiper-realistas contou também com o desenvolvimento de reproduções sonoras em sistemas 5.1 surround para reforçar ainda mais a imersão na narrativa, entretanto o uso do som como interface ainda tem grande espaço a ser desenvolvido e experimentado.

Podemos destacar ainda a adaptação de diversos jogos digitais para dispositivos móveis, seja mobile ou tablets, no qual movimenta um grande mercado do entretenimento. Em busca desses games para dispositivos móveis com predomínio da linguagem sonora, percebemos que o som é bem explorado em alguns casos, mas de forma desproporcional, ou seja, em muitos casos os projetos sonoros desempenham um papel secundário no universo audiovisual em detrimento à imagem.

Na relação entre som e imagem com destaque à linguagem sonora, encontramos um bom exemplo na experiência da escuta do game DarkEcho, que aponta outras possibilidades a serem exploradas na construção de interfaces para esses jogos, bem como suas interações e experiência mediadas através dos sons. A proposta do game tem como tema principal o terror e o suspense, sendo que o dispositivo define seus agenciamentos pelas relações estabelecidas sonoramente.

\section{DarkEcho}

O game propõe uma experiência de imersão na qual o usuário está em um labirinto completamente escuro e a sua noção espacial se dá através do som. Para completar a interface gráfica do jogo os sons emitidos são traduzidos em gráficos minimalistas em forma de linhas que seguem, de forma animada, a reverberação sonora produzida pelas "paredes" do ambiente ou limites de espaço propostos pelo seu agenciamento. As mesmas são refletidas de acordo com o tamanho do ambiente em que se encontra o usuário, orientando-o em relação às possibilidades de navegação.

A visualização das linhas que representam os sons serve para guiá-lo nos ambientes aterrorizantes, pois se navega através do desconhecido e a sonorização reforça seu caráter de suspense e terror. O game propõe oitenta níveis em que o jogador é desafiado a descobrir a saída dos diversos labirintos com graus de dificuldade progressiva e tem que sobreviver aos obstáculos impostos. Os criadores sugerem que o usuário utilize fones de ouvido para uma melhor experiência imersiva.

O game foi originalmente desenvolvido para o LudumDare², que é uma competição de games. $O$ jogo foi desenvolvido em apenas 48 horas pela empresa RAC7 Gamers, o primeiro nome do jogo era You must scape (Você deve escapar), o projeto foi classificado em segundo lugar. Ele também foi destaque em 1PC Gamer's 100 Best Free Online Games on PC. O jogo

\footnotetext{
${ }^{2}$ Ludum Dare é uma comunidade online que organiza um evento chamado Game Jam. Durante uma Ludum Dare os desenvolvedores de todo o mundo passam um fim de semana desenvolvendo jogos baseados em um tema sugerido pela comunidade.

Os desafios ocorrem em abril, agosto e dezembro.

A Lundum Dare foi fundada em abril de 2002 por Geoff Howland. http://ludumdare.com/compo/contact/
} 
tem grande destaque entre outros jogos de terror para Ipad e dispositivos móveis pela particularidade de ter sua base de construção no som e não na imagem.

\section{Ambientação Sonora e jogabilidade}

Como DarkEcho é um game desenvolvido para dispositivos móveis, suas interações utilizam as ferramentas desse tipo de plataforma, como o toque dos dedos para mover o personagem em um ambiente completamente escuro, ou seja, a tela fica totalmente escura até que o jogador a toque. A identificação do usuário é representada graficamente por um pictograma de duas pegadas de sapatos com o som intradiegético ou diegético visual dos passos que se dão na direção que se desliza o dedo. (Figura 1)

Figura 1. Imagem do gráfico do game DarkEcho.

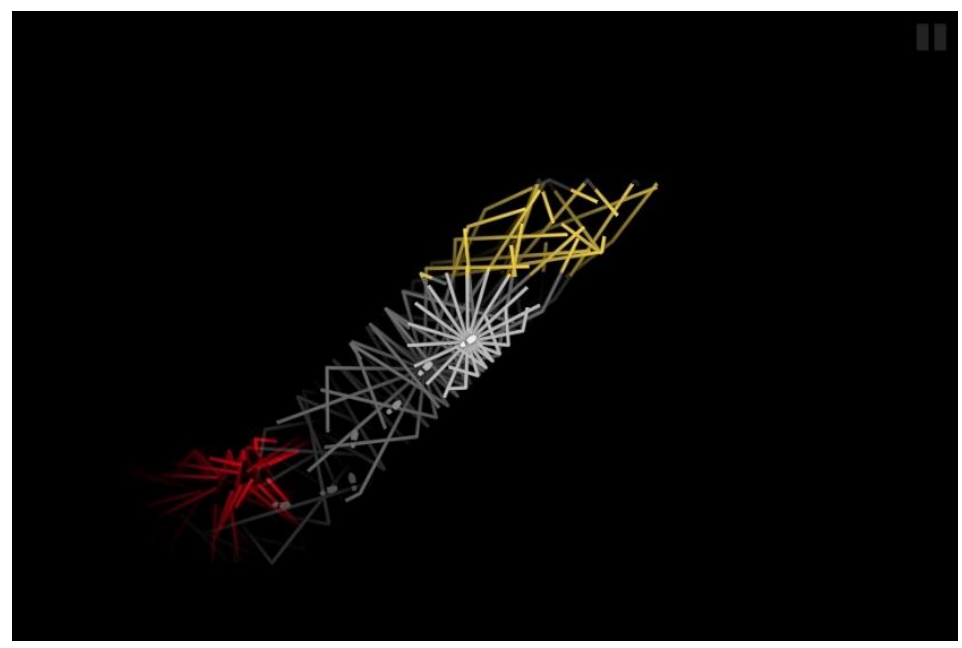

Em relação ao uso do som diegeticamente em um produto audiovisual, temos três possibilidades, do seu uso segundo Ferreira (2013):

Um filme é composto por três espaços: um diegético-visual, onde encontramos o som in, som esse que visualizamos sua fonte; outro diegético-acusmático, o qual está no desenquadramento da imagem visual, onde podemos ouvir o som mas não visualizamos a fonte sonora e, por fim, um extradiegético, em que o som está acima (over) da diegese, não fazendo parte desta diretamente.

Os demais sons apresentados no game são diegético-acusmático, que são os sons responsáveis pelo suspense nas cenas como sons de gemidos, sons de grade batendo, água pingando, uma atmosfera sonora constante que remete a uma sala muito grande e estranha, que criam imagens na mente dos usuários, causando uma sensação de estranheza e apreensão enquanto explora os diversos labirintos do jogo.

Os sons dos passos seguem a direção em que se anda, ora soando à direita ou à esquerda, normalmente quando andamos ouvimos passos mais graves, ao chegar perto de uma parede os sons ficam mais rápidos e agudos. Quando utilizamos o recurso de apenas um toque breve, ouvimos o som de palmas seguido do eco do som gerado.

À medida que o jogo se desenvolve podemos ouvir também sons de alguns insetos como vespas ou moscas em alguns locais do labirinto. Quando o jogador morre, soa um som de "facada", na sequência um grito de dor e ruídos de sangue escorrendo, notamos também pelo som que um "bicho" chupa o sangue da vítima.

A navegação se dá através da ação de deslizar o dedo com a possibilidade de locomoção vertical, horizontal e lateral, limitadas pelas extremidades do labirinto em que o personagem se encontra. O tamanho e formato das salas e alguns elementos são parcialmente representados graficamente por linhas: brancas, espaço vazio; vermelhas, "monstros" ou perigos; azuis, quando encontramos superfícies com a presença de água. As linhas geradas batem nas paredes do labirinto e refletem, desaparecendo aos poucos. 
Esses ambientes são definidos através de agenciamentos propostos pelo dispositivo, as linhas que são rebatidas no espaço, seguindo uma lógica da reverberação do som produzido pela interação do usuário com o ambiente. Esses agenciamentos são alterados pelas ações que delimitam assim os espaços, momentaneamente. O que se vê é um resultante da ação táctil que gera um som que é traduzido em um gráfico com regras acordadas entre usuário e dispositivo durante a ação.

O rebatimento produzido pelo dispositivo segue a reverberação sonora que, através de um processo de territorialização, remete o usuário a um universo sonoro previamente conhecido em outras mídias como cinema, teatro, e outros games de terror como: sons de gemidos, facada, gritos, entre outros que serão detalhados a seguir. Apesar de o game não seguir uma estrutura narrativa tradicional, busca através de um processo constante territorializar estruturas que são reconhecidas pelo jogador pelo seu repertório de obras do cinema ou mesmo nos games que têm uma escritura bem definida no modus operandi desse gênero de produção cultural.

Ao invés de códigos, falamos em componentes de meio ou componentes de expressão como assinatura do território. As cores, odores e sons marcam território. Por exemplo, a plumagem dos pássaros que define a hierarquia de um bando; a urina, o pelo dos felinos; os cantos dos pássaros, o uivo do lobo. Esses atos são componentes de meio que geram, simultaneamente, propriedades e qualidades no território. "O território não é primeiro em relação à marca qualitativa, é a marca que faz o território. As funções de um território não são primeiras, elas supõem antes uma expressividade que faz território [...] são produtos da territorialização." (Obici, 2006, p.77)

Esse processo de territorialização em um game com a hegemonia sonora recria na mente do usuário/espectador um universo imagético particular, já que o mesmo depende da vivência de cada indivíduo, tornando, assim, a obra aberta a múltiplas interpretações.

A música em outras obras de terror segue estruturas sonoras com andamentos alternados e não lineares com a repetição de sons acompanhando um ritmo frenético em ostinatos ${ }^{3}$. Esse uso da música em cenas de suspense foi amplamente utilizado nos filmes de Alfred Hitchcock com a concepção sonora de Bernard Herrmann, principalmente no filme Psicose (1960), na cena do assassinato no chuveiro, onde escutamos violinos com notas extremamente agudas repetidas em demasia, gerando maior tensão à cena.

Os sons no game são apresentados de forma estereofônica, variando entre a caixa da direita e esquerda, o mesmo não possui uma trilha de fundo musical, mas sim uma sonoridade constante em estado de imanência, sem um início, meio ou fim, algo constante e assustador, seguindo em um ruído interminável que nos dá uma sensação de angústia e medo.

A construção do ambiente do game se dá através da navegação, propondo ao usuário uma concepção provisória existindo somente no momento em que se toca a tela (Figura 2).Quando deixamos de pressionar o dedo na tela temos um alívio momentâneo, pois todo o som e as representações gráficas desaparecem. As imagens dependem do som para se manifestar. Esse artifício utilizado cria, dessa forma, um importante recurso sonoro que é a pausa como elemento de antecipação de algo que está a acontecer, gerando uma tensão imediata no jogador, pois só temos uma noção do que vai acontecer com base na experiência vivida nas fases anteriores, o espaço nos é apresentado apenas quando o som reverbera nos limites espaciais agenciados pelo dispositivo de construção do espaço com base no sonoro.

\footnotetext{
${ }^{3}$ Em música, um ostinato é um motivo ou frase musical que é persistentemente repetido numa mesma altura. A ideia repetida pode ser um padrão rítmico, parte de uma melodia ou uma melodia completa.

https://pt.wikipedia.org/wiki/Ostinato
} 
Figura 2. Imagem do gráfico do game DarkEcho.

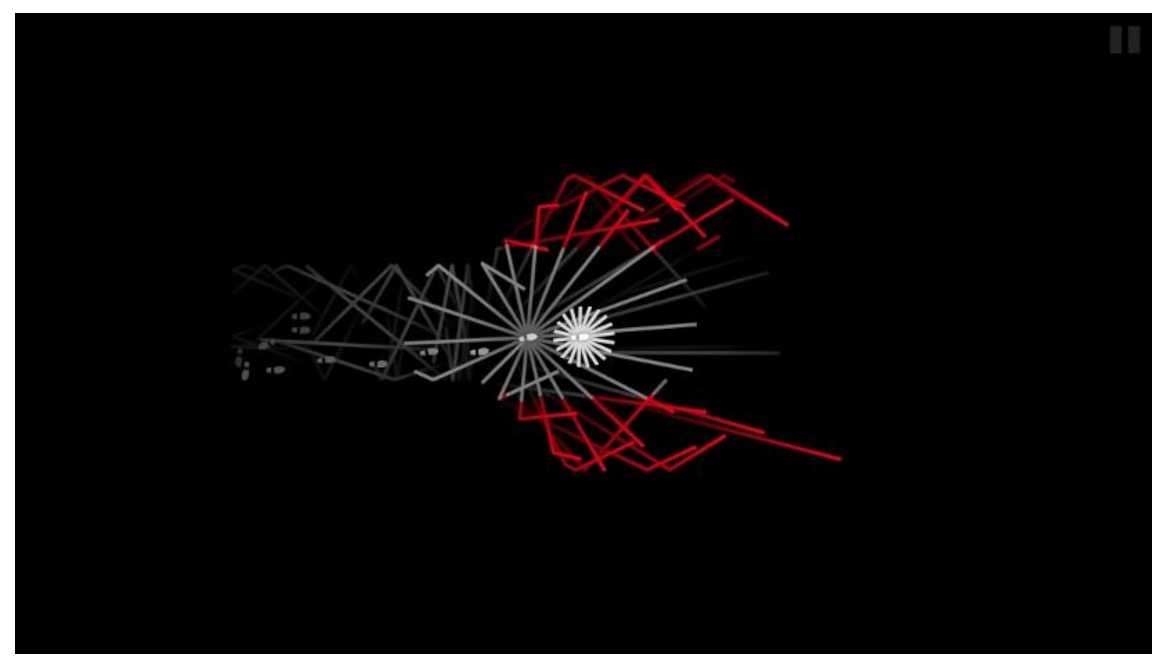

Para os "aventureiros" mais cautelosos, o dispositivo nos dá a possibilidade de através de um breve toque, simulando a ação como se batesse palmas em um ambiente, por um breve instante tomamos consciência do tamanho e formas do espaço. As linhas são reverberadas pelas paredes da sala virtual por um breve instante, nos dando uma noção do que está por vir, ou mesmo cria mapas de possíveis caminhos ou saídas.

O navegador é incentivado a construir estratégias bem particulares, construindo uma infinidade de narrativas agenciadas pelos algoritmos propostos pelo dispositivo. Em cada jogada temos uma vivência particular no qual nós determinamos o ritmo e a dimensão da interface gráfica, a visualidade é momentânea e mediada pela ação que deixa nossos rastros pelo caminho, mas quando a ação acaba elas desaparecem, voltando a ser apenas uma tela escura e silenciosa. O silêncio mais uma vez nos faz sentir inseguros do que ainda virá, porém quando encontramos a saída um signo sonoro muito familiar nos traz alívio, o som de uma porta que se abre nos levando à próxima fase.

Quando as linhas brancas terminam em linhas vermelhas que quase que instantaneamente desaparecem, a tensão retorna, pois os viventes do labirinto estão em constante movimento e quando acionamos o som, os mesmos também tomam conhecimento da nossa presença. Somos notados pelo som que produzimos.

As oitenta salas propostas pelo jogo são temáticas e seu título nos induz a uma ideia do que encontrar nesse ambiente, desta forma estamos em um processo de territorialização e desterriteriolização constante, seja através de sons remetidos em nosso museu imaginário ou apreendidos em um novo banco de sons que foram apresentados pelo game. Obici comenta que

Um território se faz, se constrói; suas marcas se dão pelo ato que se faz expressivo, componentes do meio tornados qualitativos. Ao mesmo tempo, o conceito de território está relacionado diretamente com outras terminologias, que são: desterritorialização, reterritorialização e ritornelo. (Obici, 2006, p.76)

Os conceitos apresentados por Obici, originalmente propostos por Deleuze e Guatarri, se referem aos agenciamentos do dispositivo jogo, as construções mentais realizadas pelos usuários dependem de um repertório anterior que reforçam ainda mais as sensações experimentadas ao interagir.

A noção de território, na obra de Deleuze e Guattari, possui um valor existencial e expressivo, delimita o espaço de dentro e o de fora, e marca as distâncias entre Eu e o Outro. Estabelece propriedade, apropriação, posse, domínio e identidade, bem como expressividades e subjetividades. Territorializar é delimitar o lugar seguro da casa que nos protege do caos. Por outro lado, desterritorializar é sair de um espaço delimitado, romper as barreiras da identidade, do domínio e da casa. Existe uma dinâmica implícita à qual os conceitos estão ligados. (Obici, 2006, p.76) 
Esse estado em devir mediado pela experiência de adentrar em um dos oitenta labirintos em DarkEcho faz uma construção da narrativa mediada pelos espaços sonoros do game em que visualmente o único ícone visualizado é de pegadas de sapato que vão caminhando pelo espaço entre linhas brancas, vermelhas, amarelas e azuis. A única ajuda que temos são as referências sonoras e sua reverberação que nos dá uma ideia do espaço.

Os espaços são temporários, eles existem no tempo em que as linhas são reverberadas pelo som, indiciando alguns signos próprios do jogo como: perigos, saídas, caminhos possíveis, caminhos fechados e em última instância a morte. Mas, como na maioria dos games tudo recomeça no início da fase.

Como destaca Obici (2006) o processo de descodificação proposto pelo game é de transformação do código, produzindo um ritmo, uma diferenciação que difere as coisas. Nos espaços experimentados já existem os códigos, porém quando os elementos do jogo reagem ao nosso movimento ele cria um território, e também, ao mesmo tempo subverte os códigos ali existentes.

\section{Conclusão}

Com esse exemplo podemos concluir que o desenvolvimento tecnológico nos fornece uma infinidade de possibilidades de construção de outros agenciamentos sonoros que são somados ou confrontados às construções imagéticas encontradas nos games para dispositivos móveis.

O desenvolvimento do game DarkEcho demonstra outros caminhos a serem percorridos na concepção de interfaces sendo o som é o protagonista, mesmo em um cenário de games de gráficos em $4 \mathrm{~K}$ com visualizações tridimensionais, esse projeto propõe o uso de gráficos simples que são materializados pelas relações sonoras vinculadas a sua presença. Se não temos som não temos imagens.

Nossa intenção não é trocar o grau de importância entre o sonoro e o visual, sobrepondo dessa forma os sons a imagens, mas sim uma busca da exploração das relações entre imagens e sons de forma complementar e criativa, gerando dispositivos que reforcem 0 potencial de cada linguagem individualmente e em conjunto.

\section{Referências}

Altman, R. Cinema and popular song: The losttradition. In KNIGHT, Arthur \& WOJCIK, Pamela Robertson (eds.) Soundtrackavailable: Essaysonfilmand popular music. Durham \& London: Duke University Press, 2001

Altman, R. Nascimento da recepção clássica: a campanha para padronizar o som. s.n.t. p. 41 47.

Belleboni, L. A difícil relação entre imagem e som no audiovisual contemporâneo. II Encontro Nacional da Rede Alfredo de Carvalho. Florianópolis. 2014.

Bethônico, J. A Articulação dos Signos Audiovisuais. São Paulo: Pontifícia Universidade Escola de Comunicações e Artes da USP, 1998. 273 p. (Tese de Doutorado).

Carrasco, C. R. Sygkronos: a formação da poética musical do cinema. São Paulo:

Carrasco, N. Sygkhronos. A Formação da Poética Musical do Cinema. São Paulo: Via Lettera, 2003.Católica - Programa de Pós-Graduação em Comunicação e Semiótica, 2001. Tese de Doutorado.

Chion, M. La audiovisión. Introducción a unanálisis conjunto de laimagen e el sonido. 2.

Deleuze, G., \& Guatarri, F. Mil Platôs. Vol. 1,2 e 5. São Paulo: Ed. 34, 1999.

Didi-Huberman, G. O que vemos, o que nos olha. São Paulo: Ed. 34, 1998

Didi-Huberman, G. Que emoção! Que emoção? São Paulo: Editora 34, 2016. 
Ferreira, M. As Margens do Som - Uma análise das imagens sonoras do curta-metragem Da Janela do meu Quarto (2004) de Cao Guimarães. Rio de Janeiro: UERG, 2013. Disponível em: <http://www.academia.edu/download/33023447/artigo_CONECO2013_MarinaMapurun ga.pdf>, acesso em 18 de junho 2016.

Neves, J. P. O apelo do objeto técnico. Porto: Campo das Letras, 2006.

Obici, G. Condição da Escuta - mídias e territórios sonoros: Dissertação (Mestrado em Comunicação e Semiótica) - PUC-SP, São Paulo, 2006.

Simodon, G. El modo de existência de los objetos técnicos. Buenos Aires: PrometeoLibros, 2007.

Sudjic, D. A linguagem das coisas. Rio de Janeiro: Intrínseca, 2010.

Valbom, L. V. Integração de realidade virtual no desenvolvimento de um modelo de instrumento musical imersivo. Tese de Doutoramento em Sistemas de Informação. Universidade do Minho, 2006. 267p. p.59. Disponível em:

<https://core.ac.uk/download/pdf/55608912.pdf>, acesso em: 20 maio. 2018.

\section{Sobre o autor}

Júlio Alessi, doutorando, UEMG, Brasil, <juliolafeta@gmail.com> 